\title{
Egg yolk phospholipids: a functional food material to generate deep-fat frying odorants
}

Article

Accepted Version

Chen, D.-W., Balagiannis, D. P. and Parker, J. K. (2019) Egg yolk phospholipids: a functional food material to generate deep-fat frying odorants. Journal of the Science of Food and Agriculture, 99 (14). pp. 6638-6643. ISSN 1097-0010 doi: https://doi.org/10.1002/jsfa.9939 Available at https://centaur.reading.ac.uk/85111/

It is advisable to refer to the publisher's version if you intend to cite from the work. See Guidance on citing.

To link to this article DOI: http://dx.doi.org/10.1002/jsfa.9939

Publisher: Wiley

All outputs in CentAUR are protected by Intellectual Property Rights law, including copyright law. Copyright and IPR is retained by the creators or other copyright holders. Terms and conditions for use of this material are defined in the End User Agreement.

www.reading.ac.uk/centaur 
Central Archive at the University of Reading

Reading's research outputs online 
$1 \quad$ Egg yolk phospholipids: a functional food material to generate

\author{
De-Wei Chen ${ }^{\mathrm{a}, \mathrm{b}, *}$, Dimitrios P. Balagiannis ${ }^{\mathrm{b}}$, Jane K. Parker ${ }^{\mathrm{b}}$ \\ a Department of Food Science, Guangxi University, 530004, Nanning, Guangxi, \\ China \\ ${ }^{\mathrm{b}}$ Department of Food and Nutritional Sciences, University of Reading, Whiteknights, \\ Reading RG6 6AP, UK \\ *Corresponding author: Dr De-Wei Chen, Department of Food Science, Guangxi \\ University, 530004, Nanning, Guangxi, China \\ Tel: 0086-(0)771-3237305; E-mail: chendw@gxu.edu.cn
}




\section{Abstract}

5

6 Phospholipids are an important precursor for the generation of carbonyl compounds

7 which play a significant role in the characteristic aroma of deep-fat fried foods.

\section{$8 \quad$ RESULTS}

9 Phospholipids extracted from hen egg yolks were added into sunflower oil $(2.0 \mathrm{~g} / \mathrm{kg})$ and heated with or without chicken meat at $160{ }^{\circ} \mathrm{C}$ for $10 \mathrm{~min}$, and then dynamic headspace extraction and GC-MS were used to extract and analyze the volatiles. The results showed that the characteristic deep-fat frying odorants, such as (E,E)-2,4-decadienal, $(E, Z)$-2,4-decadienal, as well as 1-octen-3-one, $(E)$-2-nonenal, octanal, methional, dimethyl disulfide and alkylpyrazines had increased by 3-65 times in the sunflower oil with added phospholipids, and increased up to 6 times in chicken meat which had been treated with phospholipids prior to heating.

\section{CONCLUSION}

There is potential for the food industry to use low levels of phospholipids, particularly egg yolk phospholipids, to increase deep-fat frying odorants in a wide range of deep fried products.

Keywords: deep-fat frying; odorants; phospholipids; egg yolk; chicken meat; 2,4-decadienal. 


\section{Introduction}

Deep-fat frying is a popular cooking method, and the deep-fat frying aroma is very attractive for the consumer. Deep-fat frying aroma comes from the oxidation and decomposition of the lipids, as well as Maillard reaction, and it always occurs at high cooking temperatures. ${ }^{1}$ (E,E)-2,4-Decadienal (deep-fried), (E,Z)-2,4-decadienal (deep-fried), pyrazines (roasty), 2- and 3-methylbutanal (malty), and methional (cooked potato-like odor) are the key odorants in fried potato chips. ${ }^{1-3}$

Thuerer et al showed that the fatty acid profile of the frying oil significantly influenced the concentration of 2,4-decadienals. ${ }^{3}$ They found that the concentration of 2,4-decadienals in safflower oil was about 12 times higher than in coconut oil, as safflower oil is richer in linoleic acid, the main precursor of 2,4-decadienals. The concentration of the Strecker aldehydes and alkylpyrazines were not clearly influenced by the frying oils, but frying temperature is an important parameter as it has a great influence on their formation. ${ }^{4}$ Compared with conventional fried (at $165{ }^{\circ} \mathrm{C}$ ) crisps, vacuum frying (at $120{ }^{\circ} \mathrm{C}$ ) crisps reduced the formation of lipid-derived compounds and Maillard reaction products, especially alkylpyrazines. ${ }^{4}$ Egg yolk phospholipids are rich in linoleic acid and arachidonic acid, ${ }^{5}$ and it can be used as a source of important precursors for the generation of lipid-derived odorants. ${ }^{6,7}$ For example, hexanal, (E,E)-2,4-decadienal, 1-octen-3-one, (E)-2-decenal and (E)-2-undecenal were produced when egg yolk phospholipids were thermally treated at $145{ }^{\circ} \mathrm{C}$ for $20 \min ^{6}$ In our previous work, ${ }^{7}$ the lipid-derived compounds contributing to the characteristic chicken meat aroma 
45

increased sharply when egg yolk phospholipids were heated in water at $100{ }^{\circ} \mathrm{C}$ for 20 min, and chicken meat aroma was improved when egg yolk phospholipids were added to minced chicken meat prior to heating under the same conditions.

The hypothesis of this work is that egg yolk phospholipids can be the primary precursors of deep-fat frying odorants, which could be used specifically to increase the key odorants of deep-fried food. Although deep-fat frying odorants have been widely studied and produced by different methods, to the best of our knowledge, no research has been published where egg yolk phospholipids have been used in the deep-fried food. The objective of this work is to study the impact on deep-fried odorants when egg yolk phospholipids are added into sunflower oil and heated at frying temperatures with and without chicken meat.

\section{Materials and methods}

\section{Reagents and Chemicals}

Authentic chemicals of reference aroma compounds were purchased from a range of laboratory chemical suppliers in U.K.. 1,2-Dichlorobenzene in methanol (130.6 $\mathrm{ng} / \mu \mathrm{L})$ and alkane standard $\mathrm{C} 5-\mathrm{C} 25(100 \mathrm{ng} / \mu \mathrm{L}$ in diethyl ether), used as GC-MS standards, were obtained from Sigma-Aldrich Co. Ltd. (Gillingham, U.K.).

\section{Phospholipids extraction}

Commercial fresh hen eggs were bought from a local supermarket for this study. The extraction method employed was that reported by Chen et al. ${ }^{7}$ Briefly, fresh egg yolk (40 g, obtained from six hen eggs) lipids were extracted with ethanol; then the crude phospholipids were dissolved in hexane; next, cold acetone was used to 
precipitate phospholipids; finally the high purity phospholipids were obtained. The minor residual solvents in the phospholipids were removed under high vacuum at room temperature for $10 \mathrm{~h}$.

\section{Phospholipids purity}

This method was according to the AOCS Official Method. ${ }^{8}$ Firstly, the phospholipids sample was ashed in the presence of zinc oxide, followed by the spectrophotometric measurement of phosphorus as a blue phosphomolybdic acid complex, and finally a conversion factor of 30 was used to convert phosphorus to phospholipids.

\section{Sample preparation}

To disperse the phospholipids, $0.50 \mathrm{~g}$ phospholipids and $9.50 \mathrm{~g}$ salt were ground and thoroughly mixed. Commercial sunflower oil and fresh chicken breast fillets without skin or bone were bought from a local supermarket for this study. The chicken meat ( 200 g) was ground in a domestic meat mincer (Kenwood, Havant, UK) and thoroughly mixed. The samples were prepared as follows:

1) Sunflower oil sample: 0.57 g salt, 15.0 g sunflower oil.

2) Sunflower oil \& phospholipids sample: 0.60 g phospholipids and salt mixture, $15.0 \mathrm{~g}$ sunflower oil.

3) Chicken meat sample: $1.50 \mathrm{~g}$ chicken meat, $0.57 \mathrm{~g}$ salt, $15.0 \mathrm{~g}$ sunflower oil.

4) Chicken meat \& phospholipids sample: $1.50 \mathrm{~g}$ chicken meat, $0.60 \mathrm{~g}$ phospholipids and salt mixture, $15.0 \mathrm{~g}$ sunflower oil.

Finally the samples were sealed in $100 \mathrm{~mL}$ glass Duran bottles and heated in an oil 
bath $\left(160^{\circ} \mathrm{C}\right)$ for $10 \mathrm{~min}$ and then cooled in an ice-bath. Each treatment was carried out in quadruplicate and all samples were prepared from the same batch of egg, sunflower oil and chicken mince.

\section{Dynamic Headspace Extraction (DHE)}

DHE was used for the extraction of the volatiles, following the method described by Chen et al with minor modifications. ${ }^{7}$ The entire contents of each Duran bottle were transferred into a $250 \mathrm{~mL}$ conical flask fitted with a Dreschel head. The flask was incubated in a water bath at $50{ }^{\circ} \mathrm{C}$, and the volatiles in the headspace were swept onto Tenax absorbent using a flow of nitrogen $(40 \mathrm{~mL} / \mathrm{min})$ for $60 \mathrm{~min}$. After sweeping, $1.0 \mu \mathrm{L}$ 1,2-dichlorobenzene in methanol $(130.6 \mathrm{ng} / \mu \mathrm{L})$ was added as an internal standard to the trap, followed by a purge of $100 \mathrm{~mL} / \mathrm{min}$ for $10 \mathrm{~min}$ to remove excess solvent and moisture.

\section{GC-MS Analysis of Volatile Compounds}

The DHE samples were analysed using an Agilent 7890A-5975 GC-MS system (Agilent Technologies Co. Ltd., Palo Alto, CA, USA) equipped with an automated thermal desorber (Turbomatrix ATD), using a DB 5 column $(60 \mathrm{~m} \times 0.25 \mathrm{~mm}$ i.d., 1 $\mu \mathrm{m}$ film thickness from $\mathrm{J} \& W$ Scientific, Agilent, Palo Alto, CA, USA) under instrumental conditions described by Chen et al. ${ }^{7}$ The identification of the compounds was based on the comparison of their mass spectra with spectra from the NIST 11 Mass Spectral Database. ${ }^{9}$ The linear retention index (LRI) was calculated for each volatile using the retention times of a series of C5-C25 n-alkanes. The identities of most of the volatiles were confirmed if their mass spectra and LRI 
111

112

matched those of authentic compounds run under the same analytical conditions in our laboratory. Volatiles were considered as tentatively identified by matching their mass spectra with the reference mass spectra in the NIST mass spectral library, and by comparison of their LRI to the NIST Chemistry WebBook database. ${ }^{10}$ Volatiles were semi-quantitatively determined by comparison of the peak areas against that of the internal standard using a response factor of 1 for each compound.

\section{Statistical Analysis}

The GC-MS data were analyzed using Independent-Samples T Tests (SPSS, 23, IBM) comparing the sunflower oil sample with the sunflower oil \& phospholipids sample, and comparing the chicken meat sample with the chicken meat \& phospholipids sample. Significant differences are shown by ${ }^{* *}, p \leq 0.01 ; *, p \leq 0.05$; ns, $p>0.05$.

\section{Results and Discussion}

\section{The purity of the extracted phospholipids}

The purity of the extracted egg yolk phospholipids was $95.2 \pm 3.0 \%$, which was coincided with the report of Gladkowski et al. ${ }^{11}$ According to their report, the purity of the phospholipids extracted by this method was very high (95.9\%), and the phospholipids contained phosphatidylcholine (78\%) and phosphatidylethanolamine $(21 \%)$.

\section{Characteristic deep-fat frying odorants derived from lipids}

The results are shown in Table 1. The most abundant odorants detected were mainly aldehydes, such as (E)-2-heptenal, hexanal and (E,E)-2,4-decadienal. 
133

134

(E,E)-2,4-Decadienal (fatty, fried), (E,Z)-2,4-decadienal (fatty, fried), 1-octen-3-one (mouldy, mushroom-like), (E,E)-2,4-nonadienal (fatty, fried, green), are the characteristic deep-fat frying odorants. ${ }^{1}$ These compounds are formed from the thermal oxidation of unsaturated fatty acids, especially from the $\omega-6$ fatty acids (linoleate and arachidonate). ${ }^{12,13}$ Both $(E, E)$-2,4-decadienal and hexanal are often used as primary marker compounds of the oxidation of $\omega-6$ fatty acids. ${ }^{14}$

Sunflower oil is widely used for deep-fat frying process, ${ }^{15}$ and it is rich in linoleic acid (about $62 \%$ of the total fatty acids), ${ }^{16}$ and the linoleate residues are present as triglycerides (as there are only trace phospholipids presented in the refined sunflower oil). Both the C9 and C13 position of the linoleate residues in triglycerides are favored positions to form the hydroperoxides during autoxidation, ${ }^{14,17}$ and the C9 and C13 hydroperoxide are the precursors for 2,4-decadienal and hexanal, respectively. So linoleate residues present in triglycerides can produce both 2,4-decadienal and hexanal.

\section{Characteristic odorants derived from the Maillard reaction}

Alkylpyrazines, originating via the Maillard reaction, are important contributors to typical roasted, nutty, meaty, earthy, and popcorn-like note of many heated food products. The dominant alkylpyrazines in the present study were methylpyrazine and 2,5-dimethylpyrazine. The Strecker aldehydes, for example, 2- and 3-methylbutanal (malty), methional (cooked potato-like odor), as well as phenylacetaldehyde (green, sweet), are the key odorants in fried potato chips, which are originated from isoleucine, leucine, methionine and phenylalanine, respectively. 2-Methylpropanal 
155 173 phospholipids highly susceptible to oxidation and to the generation of large

(pungent) is formed from valine. ${ }^{18}$ Benzaldehyde (almond) is formed from phenylacetaldehyde, ${ }^{19}$ and methional may degrade to methanethiol, which in turn could produce dimethyl disulfide and dimethyl trisulfide. ${ }^{20}$

\section{Sunflower oil samples}

The contents of hexanal and $(E, E)-2,4-$ decadienal in the headspace collected from the heated sunflower oil sample were approximately $800 \mathrm{ng}$ and $2 \mathrm{ng}$ respectively. When the phospholipids were added to the sunflower oil prior to heating, hexanal increased by about $20 \%$ whereas the concentratrion of $(E, E)$-2,4-decadienal was 65 times higher than in the heated sunflower oil alone. As both $(E, E)-2,4$-decadienal and hexanal are the markers of oxidation, this shows that the egg yolk phospholipids under the present frying condition $\left(160^{\circ} \mathrm{C}, 10 \mathrm{~min}\right)$ were more prone to oxidation. It also demonstrates how the chemical environment of the linoleate residue influences the relative rates of formation of hexanal and $(E, E)-2,4$-decadienal.

The presence of phospholipids in the oil has two effects. Firstly it is clear that incorporation of the phospholipids increased the rate of oxidation. Owing to the amphiphilic nature of phospholipids, they tend to be present in a dispersed form, increasing their surface area, and increasing their exposure to water soluble pro-oxidants. In meat, these are likely to be pro-oxidant metals, rendering the quantities of lipid-derived volatiles. ${ }^{21}$ Linoleic acid is the predominant PUFA (about $14 \%$ of the total fatty acids) in egg yolk phospholipids. ${ }^{5}$ Secondly, phospholipids direct the position of oxidation, promoting formation of the C9 
177

hydroperoxide-derived volatiles in linolate residues over those derived from $\mathrm{C} 13$ hydroperoxides. ${ }^{22}$ It was reported that for linoleate residues bound in a phospholipid, autoxidation at the $\mathrm{C} 9$ position is the most favored position for formation of hydroperoxides. ${ }^{22}$ The $\mathrm{C} 9$ hydroperoxide is the precursor for 2,4-decadienals, so 2,4-decadienals are the dominant product for linoleate assembled in phospholipids. When the phospholipids were added to the sunflower oil sample, there was a sharp increase in (E,E)-2,4-decadienal (130 ng vs. $2 \mathrm{ng}$ ) and only a relatively small increase in hexanal (988 ng vs. $804 \mathrm{ng}$ ) which corroborates the finding of Reis and Spickett. ${ }^{22}$ In our previous study, ${ }^{7}$ we also observed a much greater increase in $(E, E)$-2,4-decadienal than in hexanal when phospholipids were added to water prior to a mild heating procedure.

Once the lipid oxidation process has been initiated by the more reactive fatty acids, this can promote the oxidation of the less reactive fatty acids. ${ }^{23}$ The oxidised phospholipids not only produced lipid-derived aldehydes, but also promoted the oxidation of sunflower oil, explaining the increase in $\omega-3$ and $\omega-9$ derived volatiles in the sunflower oil \& phospholipids sample.

The presence of some Maillard reaction products in the sunflower oil \& phospholipids sample was not surprising, as low levels of Maillard reaction precursors are co-extracted with the phospholipids when polar solvents (ethanol and acetone) are used. In addition, both the primary amine group present in phosphatidylethanolamine and aldehydes produced from lipid oxidation can serve as Maillard reaction substrates. ${ }^{21}$ It is also consistent with the previous reports ${ }^{24,25}$ that 
the products of phospholipids oxidation can contribute to the Maillard reaction.

\section{Sunflower oil samples with chicken meat}

The trends in odorants in the heated chicken meat samples were consistent with those in the heated oil samples, but the magnitude of the increases were significantly diminished. Some lipid-derived aldehydes and most of the Maillard reaction products were significantly higher in the chicken meat $\&$ phospholipids sample compared to the chicken meat sample. The presence of meat provides a rich source of precursors and reactive intermediates which can influence the formation of volatiles and explain the changes in both lipid- and Maillard-derived compounds. In the chicken meat systems, the smaller increase in lipid-derived compounds with added phospholipids is consistent with previous findings. ${ }^{7}$ Examination of Table 1 shows that some odorants, such as 2,4-alkadienals, had much smaller increases when chicken meat was added to the samples. This apparent "loss" of 2,4-decadienals in the presence of meat could be attributed to the following. Firstly, the temperature was lower in the frying meat system than in the frying oil system (because of water evaporation), and the formation of those odorants were highly associated with the temperature. ${ }^{4}$ Secondly, those odorants may get trapped within the meat. ${ }^{26}$ Thirdly, there may be interaction with other components of the meat (such as $\mathrm{NH}_{3}, \mathrm{H}_{2} \mathrm{~S}$, free amino groups and reactive dicarbonyls). For example 2,4-decadienal reacts with ammonia to form 2-pentylpyridine via Maillard reaction. ${ }^{27}$ Finally, the degradation of this highly reactive alkadienal, such as 2,4-decadienal can undergo retroaldolisation to form hexanal and 2-octenal. ${ }^{28}$ The higher productions of 
221

222

2-pentylpyridine, 2-octenal and hexanal in the chicken meat \& phospholipids sample could indicate more extensive degradation of 2,4-decadienal.

The small increase in 3-methylbutanal, and a similar trend for the other Strecker aldehydes, is due to the participation of unsaturated lipid-derived compounds in the Strecker degradation. ${ }^{29}$ The parallel formation of $\alpha$-aminoketones may also promote the formation of pyrazines. This increase is observed for 4 of the 5 pyrazines detected.

\section{The key odorants in chicken \& phospholipids sample}

Both isomers of 2,4-decadienal not only impart characteristic deep-fried odor, ${ }^{1}$ but were also the odorants with highest flavour dilution factor in chicken meat broths. ${ }^{30 \text {, }}$ 31 (E,E)-2,4-Decadienal contributes a fatty chicken note with a very low odour detection threshold $(0.07 \mu \mathrm{g} / \mathrm{kg}) .{ }^{32}$ In the present study, the contents of both isomers of 2,4-decadienal had a 3-4 times increase in the chicken meat \& phospholipids samples, which indicated that the characteristic fatty fried chicken notes could arise from the increases in 2,4-decadienals. Besides (E,E)-2,4-decadienal, 1-octen-3-one, alkylpyrazines and the Strecker aldehydes are also the most significant contributors to deep-fried chicken meat flavor. Under the present processing conditions, the content of most of alkylpyrazines and the Strecker aldehydes had significantly increased, especially methional had a about 4 times increase in the phospholipids added chicken meat samples, which means that the fried meat note was enhanced by egg yolk phospholipids.

\section{Conclusion}


243 It has been demonstrated that the characteristic deep-fat frying odorants and fried 244 chicken meat odorants, such as $(E, E)$ - and (E,Z)- 2,4-decadienal, 1-octen-3-one, 245 (E)-2-nonenal, octanal, methional, disulfide dimethyl, methylpyrazine and 246 trimethylpyrazine significantly increased when a small amount $(2.0 \mathrm{~g} / \mathrm{kg})$ of egg 247 yolk phospholipids was added into sunflower oil samples with or without chicken 248 present prior to heating at frying temperatures. This is of potential interest to the 249 food industry and catering industry, however, its usage and effects on the deep-fat 250 frying aroma need further sensory research, as food aroma is a delicate balance of 251 the odorants.

\section{Acknowledgements}

253 This study was supported by the National Key R\&D Program of China (2018YFD0901003) and China Scholarship Council (No. 201706665009).

\section{Conflict of interest}

256 There is no conflict of interest about this article.

\section{References}

1. Wagner R K and Grosch W, Key odorants of French fries. J AM OIL CHEM SOC 75:1385-1392 (1998).

2. Van Loon W, Linssen J, Legger A, Posthumus MA and Voragen A, Identification and olfactometry of French fries flavour extracted at mouth conditions. FOOD CHEM 90: 417-425 (2005). 
Undesired Toxicologically Relevant Compounds during Deep-Frying of Potatoes with Different Edible Vegetable Fats and Oils. J AGR FOOD CHEM 64: 9107-9115 (2016).

4. Belkova B, Hradecky J, Hurkova K, Forstova V, Vaclavik L and Hajslova J, Impact of vacuum frying on quality of potato crisps and frying oil. FOOD CHEM 241: $51-59$ (2018).

5. Katz MA, Dugan LR and Dawson LE, Fatty acids in neutral lipids and phospholipids from chicken tissues, J FOOD SCI 5: 717-720 (1966).

6. Lin JM and Blank I, Odorants generated by thermally induced degradation of phospholipids. J AGR FOOD CHEM 51: 4364-4369 (2003).

7. Chen D, Balagiannis DP and Parker JK, Use of egg yolk phospholipids to generate chicken meat odorants. FOOD CHEM 286: 71-77 (2019).

8. AOCS Official Method Ca 12-55. Phosphorus. Reapproved 2009. (2009).

9. NIST/EPA/MSDC. Mass Spectral Database (versions for PC and for Mass Spectrometer Database Systems). National Institute of Standards and Technology, Gaithersburg. (1992).

10. NIST Chemistry WebBook. NIST Standard Reference Database, SRD Number 69. https://webbook.nist.gov/chemistry/. (2017).

11. Gladkowski W, Chojnacka A, Kielbowicz G, Trziszka T, Wawrzenczyk C, Isolation of Pure Phospholipid Fraction from Egg Yolk. J AM OIL CHEM SOC 89:179-182 (2012).

12. Zhou L, Zhao M, Bindler F and Marchioni E, Comparison of the Volatiles Formed 
by Oxidation of Phosphatidylcholine to Triglyceride in Model Systems. J AGR FOOD CHEM 62: 8295-8301 (2014).

13. Ladikos D and Lougovois V, Lipid oxidation in muscle foods: A review. FOOD CHEM 35: 295-314 (1990).

14. Choe E and Min DB, Mechanisms and factors for edible oil oxidation, COMPR REV FOOD SCI 5: 169-186 (2006).

17. Ho CT and Chen QY, LIPIDS IN FOOD FLAVORS - AN OVERVIEW, in ACS SYMPOSIUM SERIES, eds. C. T. Ho and T. G. Hartman, AMER CHEMICAL SOC, WASHINGTON pp. 2-14 (1994).

18. Whitfield FB and Mottram DS, Volatiles from interactions of Maillard reactions and lipids. CRIT REV FOOD SCI Nutr 31: 1-58 (1992).

19. Chu FL and Yaylayan VA, Model Studies on the Oxygen-Induced Formation of Benzaldehyde from Phenylacetaldehyde Using Pyrolysis GC-MS and FTIR. $J$ AGR FOOD CHEM 56: 10697-10704 (2008).

20. Mandin O, Duckham SC and Ames JM, Volatile compounds from potato-like model systems. J AGR FOOD CHEM 47: 2355-2359 (1999). 
308

309

310

21. Cui L and Decker EA, Phospholipids in foods: prooxidants or antioxidants?. J SCI FOOD AGR 96: 18-31 (2016).

22. Reis A and Spickett CM, Chemistry of phospholipid oxidation. BBA-BIOMEMBRANES 1818: 2374-2387 (2012).

23. Elmore JS, Mottram DS, Enser M and Wood JD, Effect of the polyunsaturated fatty acid composition of beef muscle on the profile of aroma volatiles. J AGR FOOD CHEM 47: 1619-1625 (1999).

24. Hidalgo FJ and Zamora R, Strecker-type degradation produced by the lipid oxidation products 4,5-epoxy-2-alkenals. J AGR FOOD CHEM 52: 7126-7131 (2004).

25. Hidalgo FJ and Zamora R, Amino Acid Degradations Produced by Lipid Oxidation Products. CRIT REV FOOD SCI Nutr 56: 1242-1252 (2016).

26. Perez-Juan M, Flores M and Toldra F, Effect of pork meat proteins on the binding of volatile compounds. FOOD CHEM 108: 1226-1233 (2008).

27. Mottram DS, Flavour formation in meat and meat products: a review. FOOD CHEM 62: 415-424 (1998).

28. Frankel EN, Recent advances in lipid oxidation. J SCI FOOD AGR 54: 495-511 (1991).

29. Gallardo E, De Schutter DP, Zamora R, Derdelinckx G, Delvaux FR and Hidalgo FJ, Influence of lipids in the generation of phenylacetaldehyde in wort-related model systems. J AGR FOOD CHEM 56: 3155-3159 (2008).

30. Feng Y, Cai Y, Fu X, Zheng L, Xiao Z and Zhao M, Comparison of aroma-active 
compounds in broiler broth and native chicken broth by aroma extract dilution analysis (AEDA), odor activity value (OAV) and omission experiment. FOOD CHEM 265: 274-280 (2018).

333 31. Fan M, Xiao Q, Xie J, Cheng J, Sun B, Du W, Wang Y and Wang T, Aroma Compounds in Chicken Broths of Beijing Youji and Commercial Broilers. J AGR FOOD CHEM 66: 10242-10251 (2018).

32. Shi $\mathrm{H}$ and Ho CT, The flavour of poultry meat. In Flavor of meat and meat products (pp. 52-70), Springer, Boston, MA (1994). 
Table 1. Mean Values (approx ng/sample extraction) $(n=4)$ of the Volatile Compounds Identified in Headspace of the Samples.

\begin{tabular}{|c|c|c|c|c|c|c|c|c|}
\hline & & & Sunflower oil & $\begin{array}{r}\text { Sunflower oil } \& \\
\text { Phospholipids }\end{array}$ & & Chicken meat & $\begin{array}{c}\text { Chicken meat \& } \\
\text { Phospholipids }\end{array}$ & \\
\hline Compound Name & LRI DB5 $^{1}$ & $\mathrm{ID}^{2}$ & Mean \pm SD $^{3}$ & $\operatorname{Mean} \pm \mathrm{SD}^{3}$ & $\mathrm{Sig}^{4}$ & Mean \pm SD $^{3}$ & Mean \pm SD $^{3}$ & $\mathrm{Sig}^{5}$ \\
\hline \multicolumn{9}{|l|}{$\omega-3$ derivatives } \\
\hline 2-Hexenal, $(E)$ - & 857 & A & $112 \pm 19$ & $310 \pm 57$ & $* *$ & $106 \pm 48$ & $116 \pm 51$ & ns \\
\hline 2,4-Heptadienal, $(E, Z)-$ & 1000 & $\mathrm{~B}$ & $1.73 \pm 0.30$ & $3.82 \pm 1.09$ & $*$ & $0.79 \pm 0.52$ & $0.91 \pm 0.26$ & ns \\
\hline 2,4-Heptadienal, $(E, E)$ - & 1015 & A & $5.52 \pm 0.79$ & $8.89 \pm 2.39$ & $*$ & $2.33 \pm 1.32$ & $2.77 \pm 0.91$ & ns \\
\hline \multicolumn{8}{|l|}{$\omega-6$ derivatives } & $\mathrm{ns}$ \\
\hline Pentane & 500 & A & $59.9 \pm 35$ & $282 \pm 99$ & $*$ & $53.3 \pm 12.2$ & $69.2 \pm 32.9$ & $\mathrm{~ns}$ \\
\hline Pentanal & 706 & A & $156 \pm 43$ & $257 \pm 39$ & $* *$ & $201 \pm 100$ & $150 \pm 48$ & $\mathrm{~ns}$ \\
\hline 1-Pentanol & 765 & $\mathrm{~A}$ & $23.7 \pm 2.2$ & $47.6 \pm 7.2$ & $* *$ & $191 \pm 60$ & $214 \pm 86$ & $\mathrm{~ns}$ \\
\hline Hexanal & 813 & A & $804 \pm 121$ & $988 \pm 158$ & $*$ & $352 \pm 110$ & $423 \pm 278$ & $\mathrm{~ns}$ \\
\hline 1-Hexanol & 869 & $\mathrm{~A}$ & $8.07 \pm 1.14$ & $10.5 \pm 2.6$ & $\mathrm{~ns}$ & $10.6 \pm 1.8$ & $22.1 \pm 4.3$ & $* *$ \\
\hline 2-Heptanone & 889 & A & $9.43 \pm 1.01$ & $25.9 \pm 5.4$ & $* *$ & $8.12 \pm 3.94$ & $13.6 \pm 3.6$ & ns \\
\hline Heptanal & 904 & A & $35.6 \pm 3.5$ & $135 \pm 36$ & $* *$ & $36.2 \pm 21.6$ & $53.5 \pm 14.9$ & $\mathrm{~ns}$ \\
\hline 2-Heptenal, $(E)$ - & 966 & A & $655 \pm 260$ & $1456 \pm 286$ & $* *$ & $603 \pm 297$ & $608 \pm 181$ & $\mathrm{~ns}$ \\
\hline 1-Octen-3-one & 978 & A & $10.2 \pm 3.7$ & $55 \pm 22$ & $* *$ & $11.8 \pm 4.5$ & $22.9 \pm 4.6$ & $*$ \\
\hline 1-Octen-3-ol & 983 & $\mathrm{~A}$ & $101 \pm 16$ & $174 \pm 26$ & $* *$ & $72.8 \pm 45.4$ & $63.7 \pm 37.0$ & $\mathrm{~ns}$ \\
\hline 2,3-Octanedione & 984 & A & $1.42 \pm 0.28$ & $33.9 \pm 8.6$ & $* *$ & $4.48 \pm 2.25$ & $9.54 \pm 4.11$ & $*$ \\
\hline 2-Pentylfuran & 990 & A & $16.7 \pm 3.6$ & $33.2 \pm 13.5$ & $*$ & $9.71 \pm 7.35$ & $13.1 \pm 6.9$ & $\mathrm{~ns}$ \\
\hline
\end{tabular}




\begin{tabular}{|c|c|c|c|c|c|c|c|c|}
\hline 2-Octenal, $(E)$ - & 1060 & A & $25.8 \pm 3.2$ & $145 \pm 48$ & $* *$ & $40.1 \pm 27.9$ & $57.2 \pm 18.5$ & $\mathrm{~ns}$ \\
\hline 2-Octen-1-ol, $(E)$ - & 1067 & $\mathrm{~A}$ & $1.49 \pm 0.50$ & $7.59 \pm 1.44$ & $* *$ & $3.15 \pm 0.89$ & $4.37 \pm 1.61$ & $\mathrm{~ns}$ \\
\hline 3-Nonen-2-one & 1142 & A & $1.05 \pm 0.21$ & $7.30 \pm 1.65$ & $* *$ & $1.34 \pm 0.39$ & $2.09 \pm 0.62$ & $\mathrm{~ns}$ \\
\hline 2,4-Nonadienal, $(E, Z)$ - & 1200 & $\mathrm{~B}$ & $0.27 \pm 0.05$ & $1.15 \pm 0.36$ & $* *$ & $0.35 \pm 0.20$ & $0.25 \pm 0.11$ & $\mathrm{~ns}$ \\
\hline 2,4-Nonadienal, $(E, E)$ - & 1222 & $\mathrm{~A}$ & $0.79 \pm 0.12$ & $4.22 \pm 1.31$ & $* *$ & $1.11 \pm 0.59$ & $1.33 \pm 0.68$ & $\mathrm{~ns}$ \\
\hline 2,4-Decadienal, $(E, Z)$ - & 1299 & $\mathrm{~B}$ & $1.20 \pm 0.20$ & $47.92 \pm 26.53$ & $*$ & $3.29 \pm 1.36$ & $10.4 \pm 3.6$ & $*$ \\
\hline 2,4-Decadienal, $(E, E)$ - & 1325 & $\mathrm{~A}$ & $2.01 \pm 0.83$ & $130 \pm 70$ & $*$ & $5.68 \pm 1.91$ & $22.4 \pm 7.6$ & $*$ \\
\hline \multicolumn{9}{|l|}{$\omega-9$ derivatives } \\
\hline 1-Octene & 791 & A & $20.7 \pm 3.8$ & $184 \pm 50$ & $* *$ & $15.4 \pm 12.4$ & $40.88 \pm 28.67$ & $\mathrm{~ns}$ \\
\hline Octane & 800 & A & $43.2 \pm 6.9$ & $147 \pm 32$ & $* *$ & $73.0 \pm 23.1$ & $70.6 \pm 20.6$ & $\mathrm{~ns}$ \\
\hline 2-Octene, (Z)- & 815 & $\mathrm{~A}$ & $22.4 \pm 3.8$ & $160 \pm 45$ & $* *$ & $28.3 \pm 22.4$ & $93.4 \pm 57.0$ & $\mathrm{~ns}$ \\
\hline Octanal & 1004 & A & $16.4 \pm 1.8$ & $59.0 \pm 19.0$ & $* *$ & $18.5 \pm 6.2$ & $28.5 \pm 6.7$ & $\mathrm{~ns}$ \\
\hline 1-Octanol & 1070 & $\mathrm{~A}$ & $2.21 \pm 0.46$ & $6.86 \pm 2.55$ & $* *$ & $3.70 \pm 0.94$ & $3.79 \pm 0.91$ & $\mathrm{~ns}$ \\
\hline Nonanal & 1108 & A & $51.8 \pm 8.2$ & $113 \pm 28$ & $* *$ & $41.5 \pm 14.7$ & $57.4 \pm 18.1$ & $\mathrm{~ns}$ \\
\hline 2-Nonenal, $(E)-$ & 1164 & $\mathrm{~A}$ & $2.79 \pm 0.39$ & $10.9 \pm 2.1$ & $* *$ & $2.66 \pm 0.64$ & $5.14 \pm 1.29$ & $*$ \\
\hline 1-Nonanol & 1173 & A & $3.50 \pm 0.62$ & $2.88 \pm 0.82$ & ns & $2.94 \pm 0.67$ & $2.73 \pm 0.52$ & $\mathrm{~ns}$ \\
\hline Decanal & 1208 & A & $25.2 \pm 2.9$ & $17.9 \pm 7.20$ & ns & $22.8 \pm 6.5$ & $22.3 \pm 1.4$ & $\mathrm{~ns}$ \\
\hline 2-Decenal, $(E)$ - & 1266 & A & $3.60 \pm 0.81$ & $17.4 \pm 7.3$ & $* *$ & $5.42 \pm 1.59$ & $8.21 \pm 2.79$ & ns \\
\hline 2-Undecenal & 1368 & $\mathrm{~A}$ & $3.55 \pm 1.35$ & $3.11 \pm 1.5$ & ns & $2.15 \pm 0.60$ & $0.96 \pm 0.64$ & * \\
\hline \multicolumn{9}{|c|}{ Maillard reaction products } \\
\hline 2-Methylpropanal & 555 & $\mathrm{~A}$ & $65.5 \pm 44.6$ & $118 \pm 18$ & ns & $45.8 \pm 11$ & $74.8 \pm 20.0$ & $\mathrm{~ns}$ \\
\hline 3-Methylbutanal & 665 & A & $3.55 \pm 1.39$ & $660 . \pm 90$ & $* *$ & $420 \pm 65$ & $664 \pm 138$ & $* *$ \\
\hline 2-Methylbutanal & 674 & $\mathrm{~A}$ & $2.50 \pm 0.75$ & $275 \pm 50$ & $* *$ & $144 \pm 9.8$ & $170 \pm 29$ & $\mathrm{~ns}$ \\
\hline Methylpyrazine & 829 & A & $0.17 \pm 0.11$ & $7.78 \pm 2.38$ & $* *$ & $8.41 \pm 0.64$ & $17.4 \pm 5.6$ & $* *$ \\
\hline
\end{tabular}




\begin{tabular}{|c|c|c|c|c|c|c|c|c|}
\hline Methional & 912 & A & nd & $33.0 \pm 4.5$ & $* *$ & $24.0 \pm 5.7$ & $90.8 \pm 26.1$ & $* *$ \\
\hline 2,5-Dimethylpyrazine & 917 & A & nd & $7.05 \pm 1.52$ & $* *$ & $4.03 \pm 1.1$ & $12.3 \pm 0.8$ & $* *$ \\
\hline 2-Ethylpyrazine & 969 & A & $0.07 \pm 0.02$ & $0.95 \pm 1.41$ & ns & $0.12 \pm 0.23$ & $0.18 \pm 0.35$ & ns \\
\hline 2-Ethy-6-methylpyrazine & 1001 & A & nd & $0.35 \pm 0.14$ & $* *$ & $0.34 \pm 0.16$ & $0.69 \pm 0.01$ & $*$ \\
\hline Trimethylpyrazine & 1006 & A & $1.60 \pm 1.09$ & $6.79 \pm 4.12$ & $*$ & $0.19 \pm 0.11$ & $1.05 \pm 0.26$ & $* *$ \\
\hline Benzeneacetaldehyde & 1049 & A & $3.72 \pm 1.86$ & $17.3 \pm 4.8$ & $* *$ & $36.7 \pm 4.1$ & $102 \pm 25$ & $* *$ \\
\hline 2-Pentylpyridine & 1204 & B & $0.04 \pm 0.02$ & $2.20 \pm 0.63$ & $* *$ & $0.05 \pm 0.01$ & $0.44 \pm 0.24$ & $*$ \\
\hline \multicolumn{9}{|l|}{ Miscellaneous } \\
\hline Dimethyl disulfide & 745 & A & $0.05 \pm 0.00$ & $14.3 \pm 10.9$ & $*$ & $12.1 \pm 1.7$ & $30.9 \pm 9.9$ & $*$ \\
\hline Toluene & 767 & A & $9.66 \pm 8.01$ & $11.8 \pm 0.87$ & ns & $10.1 \pm 2.7$ & $25.6 \pm 28.5$ & ns \\
\hline Acetylacetone & 788 & B & $5.85 \pm 0.85$ & $25.3 \pm 41.1$ & ns & $3.35 \pm 1.58$ & $16 . \pm 33$ & ns \\
\hline 3-Cyclohepten-1-one & 826 & $\mathrm{C}$ & $4.52 \pm 0.51$ & $8.47 \pm 16.8$ & ns & $5.14 \pm 2.38$ & $9.7 \pm 3.9$ & ns \\
\hline 2-Methylcyclopentanone & 844 & A & $3.46 \pm 0.57$ & $25.7 \pm 14.6$ & $*$ & $5.43 \pm 2.61$ & $6.35 \pm 2.94$ & ns \\
\hline$\alpha$-Pinene & 934 & A & $11.0 \pm 1.2$ & $9.97 \pm 0.27$ & $\mathrm{~ns}$ & $8.26 \pm 2.68$ & $5.02 \pm 1.51$ & ns \\
\hline Benzaldehyde & 971 & A & $42.4 \pm 18.8$ & $25.0 \pm 4.0$ & ns & $61.7 \pm 11.9$ & $21.3 \pm 9.0$ & $* *$ \\
\hline Dimethyl trisulfide & 976 & A & $0.04 \pm 0.01$ & $1.28 \pm 1.48$ & ns & $14.2 \pm 6.23$ & $14.1 \pm 2.7$ & ns \\
\hline D-Limonene & 1031 & A & $0.38 \pm 0.11$ & $0.32 \pm 0.09$ & ns & $10.1 \pm 4.3$ & $14.0 \pm 7.8$ & ns \\
\hline Undecane & 1100 & A & $2.35 \pm 0.33$ & $4.31 \pm 1.23$ & $*$ & $2.84 \pm 0.27$ & $2.29 \pm 0.19$ & $*$ \\
\hline Dodecane & 1199 & A & $1.11 \pm 0.38$ & $1.02 \pm 0.17$ & $\mathrm{~ns}$ & $0.92 \pm 0.17$ & $0.64 \pm 0.12$ & $*$ \\
\hline Undecanal & 1309 & A & $2.26 \pm 0.34$ & $1.02 \pm 0.41$ & $* *$ & $2.07 \pm 0.64$ & $1.47 \pm 0.19$ & ns \\
\hline Tetradecane & 1399 & A & $1.23 \pm 0.39$ & $0.53 \pm 0.29$ & $*$ & $0.79 \pm 0.39$ & $0.55 \pm 0.21$ & ns \\
\hline Dodecanal & 1411 & A & $2.24 \pm 0.40$ & $0.75 \pm 0.40$ & $* *$ & $2.38 \pm 1.14$ & $1.06 \pm 0.04$ & $*$ \\
\hline Pentadecane & 1499 & A & $1.05 \pm 0.27$ & $0.44 \pm 0.32$ & $*$ & $1.07 \pm 0.73$ & $0.36 \pm 0.03$ & ns \\
\hline
\end{tabular}


${ }^{1}$ Linear retention indices determined on a DB 5 column.

${ }^{2}$ Confirmation of identity where $\mathrm{A}=$ mass spectrum and LRI agree with those of an authentic compound; $\mathrm{B}=$ mass spectrum agrees with reference spectrum in the NIST mass spectral database and the LRI value agrees with that in the database (NIST Chemistry WebBook, 2017); C = mass spectrum agrees with reference spectrum in the NIST mass spectral database (NIST/EPA/MSDC, 1992).

${ }^{3}$ Approximate amount (mean, $\mathrm{n}=4$ ) collected from the headspace, calculated by comparison of peak area with that of 1,2-dichlorobenzene $(130.6 \mathrm{ng})$ with a response factor of $1, \mathrm{nd}=$ not detected.

${ }^{4}$ Independent-Samples T Tests was used to compare group samples (sunflower oils sample vs. sunflower oils \& phospholipids sample), significant differences are shown by **, $p \leq 0.01{ }^{*}, p \leq 0.05 ; \mathrm{ns}, p>0.05$.

${ }^{5}$ Independent-Samples T Tests was used to compare group samples (chicken meat sample vs. chicken meat \& phospholipids sample), significant differences are shown by $* *, p \leq 0.01 ; *, p \leq 0.05 ; \mathrm{ns}, p>0.05$. 